\title{
A scoring system derived from electronic health records to identify patients at high risk for noninvasive ventilation failure
}

Mihaela S. Stefan ${ }^{1,2^{*}}$, Aruna Priya ${ }^{1}$, Penelope S. Pekow ${ }^{1,3}$, Jay S. Steingrub ${ }^{4}$, Nicholas S. Hill ${ }^{5}$, Tara Lagu ${ }^{1,2}$, Karthik Raghunathan ${ }^{6}$, Anusha G. Bhat ${ }^{2}$ and Peter K. Lindenauer ${ }^{1,2,7}$

\begin{abstract}
Objective: To develop and validate a clinical risk prediction score for noninvasive ventilation (NIV) failure defined as intubation after a trial of NIV in non-surgical patients.

Design: Retrospective cohort study of a multihospital electronic health record database.

Patients: Non-surgical adult patients receiving NIV as the first method of ventilation within two days of hospitalization.

Measurement: Primary outcome was intubation after a trial of NIV. We used a non-random split of the cohort based on year of admission for model development and validation. We included subjects admitted in years 2010-2014 to develop a risk prediction model and built a parsimonious risk scoring model using multivariable logistic regression. We validated the model in the cohort of subjects hospitalized in 2015 and 2016.

Main results: Of all the 47,749 patients started on NIV, 11.7\% were intubated. Compared with NIV success, those who were intubated had worse mortality (25.2\% vs. 8.9\%). Strongest independent predictors for intubation were organ failure, principal diagnosis group (substance abuse/psychosis, neurological conditions, pneumonia, and sepsis), use of invasive ventilation in the prior year, low body mass index, and tachypnea. The c-statistic was $0.81,0.80$ and 0.81 respectively, in the derivation, validation and full cohorts. We constructed three risk categories of the scoring system built on the full cohort; the median and interquartile range of risk of intubation was: $2.3 \%$ [1.9\%-2.8\%] for low risk group; 9.3\% [6.3\%-13.5\%] for intermediate risk category; and 35.7\% [31.0\%-45.8\%] for high risk category.
\end{abstract}

Conclusions: In patients started on NIV, we found that in addition to factors known to be associated with intubation, neurological, substance abuse, or psychiatric diagnoses were highly predictive for intubation. The prognostic score that we have developed may provide quantitative guidance for decision-making in patients who are started on NIV.

Keywords: Intubation, noninvasive ventilation failure, Predictive score, Acute respiratory failure, Mechanical ventilation

*Correspondence: Mihaela.Stefan@baystatehealth.org

${ }^{1}$ Institute for Healthcare Delivery and Population Science, University

of Massachusetts Medical School - Baystate, Springfield, MA, USA

Full list of author information is available at the end of the article

\section{Introduction}

Noninvasive ventilation (NIV) plays a key role in the treatment of acute respiratory failure (ARF) and its use is supported by multiple randomized controlled trials [1-4]. The evidence of benefit is strong for patients with acute hypercapnic respiratory failure $[1,5]$ and cardiogenic pulmonary edema $[6,7]$, while consistent benefit 
in other conditions such as acute hypoxemic respiratory failure was not found [8-10]. Even so, the use of NIV has dramatically increased in the last two decades in the US for all diagnoses regardless of supporting evidence [11-14].

Therapy with NIV is considered successful if endotracheal intubation is avoided. Conversely, the term NIV failure is used when a patient initially treated with NIV requires invasive mechanical ventilation (IMV) or dies without being intubated. NIV failure rates range from 5 to $50 \%$ and patients who are intubated have an increased risk of death compared to those treated with IMV from the outset $[9,11,15-17]$. Determining which patients are appropriate for NIV therapy is a complex decision that requires assessment of an individual's chances of failure and/or survival; improper patient selection is a main reason for poor outcomes [18-20]. Prior studies have identified several risk factors associated with NIV failure including coexistent pneumonia, tachypnea, hypotension, severe acidemia, higher severity of illness score, or failure to improve in one hour. However, most of these studies were small, were developed in cohorts from randomized trials, or were geared towards specific diagnoses $[15,21-24]$.

A simple risk score developed in a real-world cohort to identify patients' risk for NIV failure may support clinical decision for initiation of NIV and trigger goals of care discussions at the time of NIV initiation. It may also help with decisions regarding monitoring; patients at low risk of failure could be potentially admitted in a stepdown unit, whereas those at high risk could benefit from admission to an intensive care unit. Therefore, using data from a large multihospital electronic health record database that contains vitals and laboratory results, we sought to develop a clinical risk score for NIV failure defined as intubation after a trial of NIV based on information routinely available to clinicians at the time of NIV initiation.

\section{Materials and methods Design, data source, and population}

We conducted a retrospective cohort study using an electronic health record dataset, Cerner HealthFacts from January 2010 to July 2016. Health Facts contains data on patient demographics, diagnoses and procedures and detailed, time-stamped, clinical, pharmacy and laboratory results. For this analysis, we included 127 hospitals that contributed data to all domains (laboratory, pharmacy, vitals, and administrative data). We included non-surgical patients 18 years or older with NIV initiated in the first two days of hospitalization. We excluded patients receiving palliative care or hospice, patients with obstructive sleep apnea (we could not ascertain if NIV was used for OSA or for acute respiratory failure), and patients transferred to or from another facility. We used ICD-9 CM and ICD-10 CM procedure codes to identify NIV treatment; prior studies have shown that these procedure codes have sensitivity of $86.5 \%$ and specificity of $91.5 \%$ [25].

\section{Candidate risk factors}

Potential candidate variables were identified based on a review of the literature and clinical relevance $[15,16,21-$ 24]. Patients were grouped into the following 11 major categories based on the evidence for NIV use and size of the cohort: (1) congestive heart failure (CHF), (2) acute myocardial infarction (AMI) (3) chronic obstructive pulmonary disease (COPD), (4) asthma, (5) pneumonia, (6) sepsis, (7) stroke, (8) neurological non-stroke diagnosis, (9) substance abuse, (10) psychiatric diagnoses, (11) others. To assess severity of illness we used the following variables: number of hospitalizations and NIV or IMV use in the year prior to the index admission; vasopressor use within first two days of hospitalization and organ failure (acute respiratory failure was not counted) [26, 27]. We also included the following comorbidities known to be associated with NIV failure: chronic pulmonary disease, neurological disorders, psychiatric disorders, substance abuse, obesity, and weight loss. Vitals and laboratory variables known to be predictive for NIV failure such as respiratory rate, heart rate, blood pressure or bicarbonate were grouped into categories based on the Laboratory Acute Physiology Score (LAPS), which uses the results of laboratory testing around the time of admission to quantify the risk of inpatient mortality $[28,29]$. For example, respiratory rate in our model was categorized as $\leq 29$ versus $\geq 30$ with points assigned for patients with high respiratory rate [28]. We grouped missing values as separate category for factors that contained them and included in all analyses.

\section{Outcomes}

The primary outcome was intubation following a trial of NIV.

Our secondary outcome was NIV failure defined as intubation or death.

\section{Statistical analysis}

We computed summary statistics to characterize the cohort and calculated standardized mean differences to compare groups with and without the outcome of interest; a difference of $>10 \%$ is deemed significant [30].

Derivation and validation data sets: we split the cohort non-randomly based on year of admission with patients admitted in years 2010-2014 for model derivation and patients admitted in years 2015-2016 for validation. We first computed Spearman's rank correlations between 
factors to check for any collinearity between predictors We developed a series of multivariable logistic regression models to predict intubation in the derivation cohort. We initially included all the candidate risk factors, and then removed those that did not add significantly to the model [31]. We used a backward selection process wherein we selected factors based on their contribution to the model via Type 3 sums of squares. Further, to increase the likelihood that the model will be used in real-time for risk stratification purpose, we reduced the number of variables: first, we selected those with the strongest predictive ability; second, we combined candidate factors that were clinically comparable and had a similar magnitude of effect. Factors that had greater contribution to the model were selected with a cut-off at the top 10 variables. The final model was fit and checked for model performance using the c-statistics and compared it against the full model performance. Discrimination was evaluated by the area under the receiver operating characteristic (ROC) curve [32] and calibration was measured by review of the calibration plots. Parameter estimates obtained from the derivation cohort were then used to compute individual intubation risk in the validation cohort of patients admitted in year 2015 and 2016. Models were assessed for possible overfitting using the least absolute shrinkage and selection operator (LASSO) method [33]. To assess the robustness of the model we used a fivefold crossvalidation technique [34]. We divided the full cohort into 5 segments ("folds") and then refit the model that we developed in the derivation cohort in 4 of the "folds" ( $80 \%$ data) and validated it on the remaining fold $(20 \%$ data). This was performed a total of 5 times, leaving out a different "fold" each time; we then computed c-statistics as a measure of assessment of model fit for each validation "fold". Finally, we fit the model in full cohort and then developed a point-scoring system for intubation using a regression coefficient-based scoring method [35]. The total risk score was calculated by adding each component, and intubation rates were determined for the various scores. We then computed the probability of intubation at different cut-points for the total score and constructed 3 categories of intubation risk (low, medium and high). We employed similar a analytic strategy for the NIV failure outcome defined as intubation or death.

All analyses were conducted using SAS statistical software (Version 9.4; SAS Institute Inc, Cary, NC) and Stata statistical software (Version 15; STATA Corp, College Station, Texas).

The study has been performed in accordance with the Declaration of Helsinki and has been approved by the Baystate Institutional Review Board. Informed consent was not required as this was a retrospective study of deidentified data.

\section{Results}

There were 94,744 hospitalizations of non-surgical patients with NIV initiated within the first 2 days of admission at 127 hospitals. After exclusion criteria were applied (Fig. 1), our full cohort consisted of 47,749 patients.

\section{Cohort characteristics}

47,749 patients were included in our analysis; median age was of 65 years, $48.2 \%$ were female and $74.8 \%$ were of white race. The most common principal diagnoses were sepsis or pneumonia (23.5\%), AMI (22.7\%), and COPD/asthma (17.5\%); $40 \%$ of patients had one or more prior admissions and $11.5 \%$ had received NIV in the prior year. About thirty-seven percent of the patients had one or more organ failures (in addition to acute respiratory failure), $16.4 \%$ were treated with vasopressors. Among the 43,277 patients initiated on NIV by day $1,75.5 \%$ were started in the emergency department. Summary statistics of demographics, comorbidities, and presenting features are shown in Additional file 1: Table E1. In-hospital mortality was $10.8 \%$ and the median length of stay was 5 days (IQR: $3-9)$. Overall, $5,572(11.7 \%)$ patients were intubated and 1,402 (25.2\%) of those who intubated died.

\section{Characteristics of patients who were intubated}

Compared to patients who were not intubated, patients who were intubated were younger (median age 62 vs. 66 years), more likely to be of Black race $(22.0 \%$ vs. $15.4 \%)$, and more likely to have been treated with IMV in the prior year $(6.8 \%$ vs. $2.7 \%)$. Those who were intuabted were sicker, with higher rates of comorbidities including neurological disorders (21.8\% vs. $9.8 \%)$, liver disease $(7.3 \%$ vs. $3.1 \%)$, and psychiatric disorders $(20.4 \%$ vs. $11.8 \%)$; they had higher use of vasopressors $(25.0 \%$ vs. $16.6 \%$ ); were more likely to have one or more organ failures $(67.3 \%$ vs. $29.5 \%)$ or comorbid pneumonia $(33.0 \%$ vs. 20.0\%); and higher admission LAPS score (median score 50 vs. 40) (Additional file 1: Table E1). Compared with those in whom NIV was successful, those who were intubated had higher mortality $(25.2 \%$ vs. 8.9\%; p-value $<0.001)$ and longer length of hospital stay [median (IQR): 8 (3-16) vs. $5(2-8)$; p-value < 0.001 ].

Rates of intubation or death after intubation varied dramatically by condition; for example, patients with substance abuse or a psychiatric diagnosis had the highest intubationrate of $29.3 \%$ but a low mortality after intubation of $7.3 \%$, while patients with AMI had the lowest intubation rate of $3.9 \%$ but a high mortality among those intubated of $34.2 \%$; patients with stroke had both high 
Table 1 Rates of overall death, intubation, no intubation, death with and without intubation in patients treated with noninvasive ventilation

\begin{tabular}{|c|c|c|c|c|c|c|c|}
\hline \multirow[t]{2}{*}{ Diagnosis } & Entire cohort & Death overall & Intubation & Death after intubation & No. intubation & $\begin{array}{l}\text { Death } \\
\text { without intubation }\end{array}$ & \multirow[t]{2}{*}{ p-value* } \\
\hline & $\mathrm{N}$ (column \%) & Row \% & Row \% & Row \% & Row \% & Row \% & \\
\hline Total number of patients & $47,749(100)$ & $5,150(10.8)$ & $5,572(11.7)$ & $1,402(25.2)$ & $42,177(88.3)$ & $3,748(8.9)$ & \\
\hline COPD/ASTHMA & $8346(17.5)$ & $470(5.6)$ & $941(11.3)$ & $155(16.5)$ & 7405 (88.7) & $315(4.3)$ & $<0.001$ \\
\hline $\mathrm{CHF}$ & $4896(10.3)$ & $336(6.9)$ & $351(7.2)$ & $90(25.6)$ & 4545 (92.8) & $246(5.4)$ & $<0.001$ \\
\hline AMl & $10,820(22.7)$ & $663(6.1)$ & $424(3.9)$ & $145(34.2)$ & $10,396(96.1)$ & $518(5.0)$ & $<0.001$ \\
\hline Pneumonia/sepsis & $11,219(23.5)$ & $2331(20.8)$ & $2028(18.1)$ & $686(33.8)$ & 9191 (81.9) & 1645 (17.9) & $<0.001$ \\
\hline Neuro non-stroke & $1672(3.5)$ & $85(5.1)$ & $304(18.2)$ & $20(6.6)$ & $1368(81.8)$ & $65(4.8)$ & 0.19 \\
\hline Stroke & $1832(3.8)$ & $597(32.6)$ & $384(21.0)$ & $137(35.7)$ & $1448(79.0)$ & $460(31.8)$ & 0.15 \\
\hline $\begin{array}{l}\text { Substance abuse/psy- } \\
\text { chosis }\end{array}$ & $2469(5.2)$ & $153(6.2)$ & $723(29.3)$ & $53(7.3)$ & $1746(70.7)$ & $100(5.7)$ & 0.13 \\
\hline Other diagnoses & 6495 (13.6) & $515(7.9)$ & $417(6.4)$ & $116(27.8)$ & 6078 (93.6) & 399 (6.6) & $<0.001$ \\
\hline
\end{tabular}

* Chi-square test testing for association between death after intubation and death without intubation within each principal diagnosis group

intubation rate $(21.0 \%)$ and mortality after intubation (35.7\%). (Table 1).

\section{Predictors of intubation}

When we assessed for collinearity, due to our large sample size, though we saw statistically significant results between some factors, the correlations were small and not meaningful. Among the 31,053 patients in derivation cohort, the strongest predictors for intubation were presence of additional organ failure (in addition to acute respiratory failure) and principal diagnosis groups. A final model was built in full cohort including these selected 10 factors. Compared to the referent group with principal diagnosis of AMI, patients with stroke had about 6.2 times higher odds of NIV failure and those with a nonstroke neurological conditions, 5.4 times higher odds of intubation. Patients with two or more organ failures in addition to ARF at the time of admission had 5.3 times higher odds of intubation compared to those without additional organ failure. Also, the following factors increased the odds of intubation: prior year IMV use by a factor of 3.0, pneumonia as a comorbid condition with an odds ratio of 2.2, and tachypnea with an odds ratio of 1.9. The model performed well with a c-statistic of 0.81 . The main predictors of intubation and the scoring system from the associated model coefficients from full cohort are presented in Table 2.

\section{Model validation}

Characteristics of patients in derivation and validation cohorts are in Additional file 1: Table E2. We observed that compared with the derivation cohort, the validation cohort patients were less likely to be Black, more likely to have AMI, and less likely to have hypercarbia; there were no significant differences in the outcome rate. When the intubation simplified score was applied to the validation set, the c-statistic was 0.80 . Predicted and observed intubation rates in the validation cohort were in close agreement except in the highest deciles (Additional file 1: Figure E1 in online data supplement). C-statistics from the fivefold validation showed good discrimination with values of 0.80 or greater across the fivefolds showing robustness of the final model.

\section{Risk score}

Ten variables were included in the final risk score: organ failure, principal diagnosis, secondary diagnosis of pneumonia or weight loss, requiring IMV in the prior year, low BMI, presence of tachypnea, presence of hypotension, low bicarbonate, and not having admissions in prior year. A patient who falls into each of the scored variable category can have a maximum score of 38 with a risk of intubation of about $97.9 \%$. Patients who were intubated had a significantly higher risk score (median: 14, IQR: 10-17) than patients who were not intubated (median: 7, IQR: 3-10). The median, interquartile range and overall range of risk of intubation in the 3 risk categories of the scoring system were: $2.3 \%$ (IQR: $1.9 \%-2.8 \%$; range: $<4.0 \%$ ) for the low risk category (score $\leq 5$ ); $9.3 \%$ (IQR: $6.3 \%-13.5 \%$; range: $4.0 \%-$ $23 \%$ ) for intermediate risk category (score 6-14); and 35.7\% (IQR: 31.0\%-45.8\%; range: > 23\%) for high risk category (score $\geq 15$ ) (Fig. 2).

Table 3 shows the predictors and the risk score for NIV failure defined as intubation or death. Although the points for individual factors changed, the same variables were included. 
Table 2 Predictors for intubation in derivation and full cohorts

\begin{tabular}{|c|c|c|c|}
\hline \multirow[t]{2}{*}{ Factor } & \multirow{2}{*}{$\begin{array}{l}\text { Derivation cohort } \\
\text { Odds ratio }(95 \% \mathrm{Cl})\end{array}$} & \multicolumn{2}{|l|}{ Full cohort } \\
\hline & & Odds ratio $(95 \% \mathrm{Cl})$ & Points \\
\hline \multicolumn{4}{|l|}{ Number of organs failed } \\
\hline None & Referent & Referent & \\
\hline One & $2.29(2.08,2.53)$ & $2.37(2.19,2.56)$ & 4 \\
\hline Two or more & $5.46(4.95,6.02)$ & $5.34(4.94,5.78)$ & 8 \\
\hline \multicolumn{4}{|l|}{ Primary diagnostic group } \\
\hline Acute myocardial infarct & Referent & Referent & \\
\hline COPD/asthma & $3.24(2.77,3.80)$ & $2.94(2.59,3.34)$ & 5 \\
\hline Congestive heart failure & $1.80(1.49,2.17)$ & $1.52(1.30,1.78)$ & 2 \\
\hline Pneumonia or Sepsis & $3.94(3.40,4.56)$ & $3.54(3.15,3.98)$ & 6 \\
\hline Neuro non-stroke & $5.53(4.55,6.72)$ & $5.35(4.56,6.32)$ & 8 \\
\hline Stroke & $6.84(5.62,8.33)$ & $6.18(5.28,7.24)$ & 8 \\
\hline Substance abuse or psychosis & $10.09(8.47,12.01)$ & $8.70(7.58,9.99)$ & 10 \\
\hline Other & $1.78(1.49,2.14)$ & $1.54(1.33,1.77)$ & 2 \\
\hline Pneumonia (secondary dgn) & $2.27(2.04,2.53)$ & $2.21(2.02,2.42)$ & 4 \\
\hline Prior year invasive mechanical vent & $2.98(2.51,3.53)$ & $3.05(2.65,3.51)$ & 5 \\
\hline \multicolumn{4}{|l|}{ Systolic blood pressure } \\
\hline$\geq 91$ & Referent & Referent & \\
\hline$\leq 90$ & $1.55(1.42,1.68)$ & $1.51(1.42,1.62)$ & 2 \\
\hline \multicolumn{4}{|l|}{ Body mass index } \\
\hline $18.0-25.0$ & Referent & Referent & \\
\hline$<18.5$ & $1.18(1.02,1.36)$ & $1.23(1.10,1.39)$ & 1 \\
\hline \multicolumn{4}{|l|}{ Bicarbonate } \\
\hline $22-27$ & Referent & Referent & \\
\hline$<22$ & $0.96(0.88,1.04)$ & $1.02(0.96,1.10)$ & 1 \\
\hline Weight loss (secondary dgn) & $1.51(1.35,1.68)$ & $1.48(1.35,1.62)$ & 2 \\
\hline No prior year admissions & $1.42(1.31,1.55)$ & $1.41(1.32,1.51)$ & 2 \\
\hline \multicolumn{4}{|l|}{ Respiratory rate } \\
\hline$\leq 29$ & Referent & Referent & \\
\hline$\geq 30$ & $1.75(1.33,2.30)$ & $1.92(1.53,2.40)$ & 3 \\
\hline
\end{tabular}

For physiological variables we chose the worst value in the $24 \mathrm{~h}$ prior to NIV initiation

\section{Discussion}

Using a large cohort of non-surgical patients treated with NIV at 127 US hospitals, we found that a simple model using data available at hospital presentation successfully predicted intubation after initial treatment with NIV. The final risk score includes number of organ failure, principal diagnosis, acute physiological parameters, and chronic disease comorbidities, and provides a simple method to stratify a patient's risk of NIV failure into low and high risk categories relative to an intermediate group at average risk. Because of the large size of our cohort and the large network of hospitals contributing data, our model is statistically robust and highly generalizable. This model has significant potential for being incorporated in an online prognostic calculator (see example Additional file 1: figure E2 in the supplement) to help routine decision-making by providers and support appropriate monitoring and/or counseling of patients and families. We have also developed a risk score for NIV failure defined as intubation or death which included the same factors as the intubation only model, although the weight of the predictors changed slightly. Of note, our risk score applies to patients started on NIV soon after admission and not to patients who develop respiratory distress and are treated with NIV later in the course of hospitalization.

The present model differs from prior models used to predict intubation in patients started on NIV in several ways $[15,21-24]$. First, our model was designed to be used in any non-surgical patient started on NIV, regardless of the principal diagnosis, allowing for broader utility. Therefore, our study was not restricted to specific conditions such as COPD or CHF where the evidence 
Table 3 Predictors for noninvasive ventilation failure (intubation or death)

\begin{tabular}{|c|c|c|c|c|}
\hline \multirow[t]{2}{*}{ Factor } & \multicolumn{3}{|c|}{ Intubation or death } & \multirow[t]{2}{*}{ Score } \\
\hline & OR & LL & UL & \\
\hline \multicolumn{5}{|l|}{ Number of organs failed } \\
\hline None & Referent & & & \\
\hline One & 1.646 & 1.543 & 1.755 & 2 \\
\hline Two or more & 3.733 & 3.501 & 3.981 & 6 \\
\hline \multicolumn{5}{|l|}{ Primary diagnostic group } \\
\hline Acute myocardial infarct & Referent & & & \\
\hline COPD/asthma & 1.804 & 1.634 & 1.991 & 3 \\
\hline Congestive heart failure & 1.275 & 1.135 & 1.433 & 1 \\
\hline Pneumonia or sepsis & 3.464 & 3.181 & 3.771 & 5 \\
\hline Neuro non-stroke & 2.79 & 2.423 & 3.213 & 5 \\
\hline Stroke & 9.664 & 8.565 & 10.903 & 10 \\
\hline Substance abuse or psychosis & 4.293 & 3.828 & 4.815 & 6 \\
\hline Other & 1.343 & 1.21 & 1.491 & 1 \\
\hline Pneumonia (secondary dgn) & 1.966 & 1.818 & 2.127 & 3 \\
\hline Prior year invasive mechanical vent & 1.913 & 1.682 & 2.176 & 3 \\
\hline \multicolumn{5}{|l|}{ Systolic blood pressure } \\
\hline$\geq 91$ & Referent & & & \\
\hline$\leq 90$ & 2.07 & 1.959 & 2.187 & 3 \\
\hline \multicolumn{5}{|l|}{ Body mass index } \\
\hline $18.0-25.0$ & Referent & & & \\
\hline$<18.5$ & 1.372 & 1.241 & 1.517 & 2 \\
\hline \multicolumn{5}{|l|}{ Bicarbonate } \\
\hline $22-27$ & Referent & & & \\
\hline$<22$ & 0.737 & 0.697 & 0.779 & 1 \\
\hline Weight loss (secondary dgn) & 1.19 & 1.097 & 1.291 & 1 \\
\hline \multicolumn{5}{|l|}{ Respiratory rate } \\
\hline$\leq 29$ & Referent & & & \\
\hline$\geq 30$ & 2.507 & 2.064 & 3.044 & $\begin{array}{l}4 \\
\text { c-stat: } 0.78\end{array}$ \\
\hline
\end{tabular}

For physiological variables we chose the worst value in the $24 \mathrm{~h}$ prior to NIV initiation

for use of NIV is strong. Instead, we developed our predictive model in a large group of patients treated with NIV in routine clinical settings. Several predictive scores exist for specific diagnoses. For example, Confalonieri and colleagues developed a prediction chart of failure risk in patients with COPD [22]. They found that patients with an APACHE II score $\geq 29$, a Glasgow coma score $<11$, and a respiratory rate $\geq 30$ breaths $/ \mathrm{min}$ have a predicted risk of NIV failure of $>70 \%$. However, inclusion of the APACHE II score makes it less practical due to the multiple variables needed, including laboratory tests. Second, our approach is novel in that is using a large EHR dataset. The variables in our model are easily obtainable and the scoring could be applicable not only for clinical purposes but also for studies with administrative data. Third, we have developed a tool to quantitatively estimate the risk for intubation. If the risk is high, clinicians have to make the difficult decision between NIV and IMV given that those who fail NIV have mortality which is similar or even higher than those started on IMV $[9,16]$. Prior studies have shown that at least part of the increase in mortality is related to delayed intubation; this is why, if NIV is started in patients at high risk for failure, these patients need to be closely watched in a highly monitored environment. In this study we found that when NIV was started for unusual diagnoses such as drug overdose or seizure, the risk of NIV failure was high; for this group, the decision to intubate has to be seriously considered. Fourth, the prognostic model can be used as an aid in making decisions about placement of patients in ICU or intermediate care, thereby matching the intensity of monitoring with the needs of the patient [36,37]. Of note, in a step-down unit, patients are generally monitored with the same technology as in an ICU but frequency of monitoring and the intensity of care provided by the nurses and respiratory therapists is lower [38, 39]. Currently, there is large variation in policies regarding administration of NIV across hospitals, with some institutions restricting NIV utilization to the ICU while others allow it on step-down units [20,37]. Our scoring system can help tailor these decisions. For example, patients with substance abuse, pneumonia, renal failure (one organ dysfunction), cachexia, a prior year intubation, and tachypnea will have a total score of 28 , giving them an $85 \%$ probability for NIV failure (Additional file 1: Figure E2); consequently, these patients should be closely watched in the ICU or intubated in the first place.

Our results largely confirm a number of risk factors for NIV failure that have been previously described by other studies $[9,11,15,17]$. However, a surprising finding of our study is the large number of patients treated with NIV who had neurological, substance abuse, or psychiatric diagnoses; most of which are not typical for acute respiratory patients. Notably, only $35.3 \%$ of the 5,973 patients with these diagnoses had a secondary diagnosis of conditions that would suggest an indication for NIV such as CHF, asthma, COPD, AMI, pneumonia or sepsis, raising questions on the purpose of using NIV in this cohort. Furthermore, this group had a higher risk for intubation compared with patients with CHF or COPD: almost one in three patients in this category needed to be intubated after a trial of NIV, demonstrating that they are not good candidates for NIV. We are not able to identify the reason why these patients were started on NIV. One could hypothesize that these patients became lethargic 


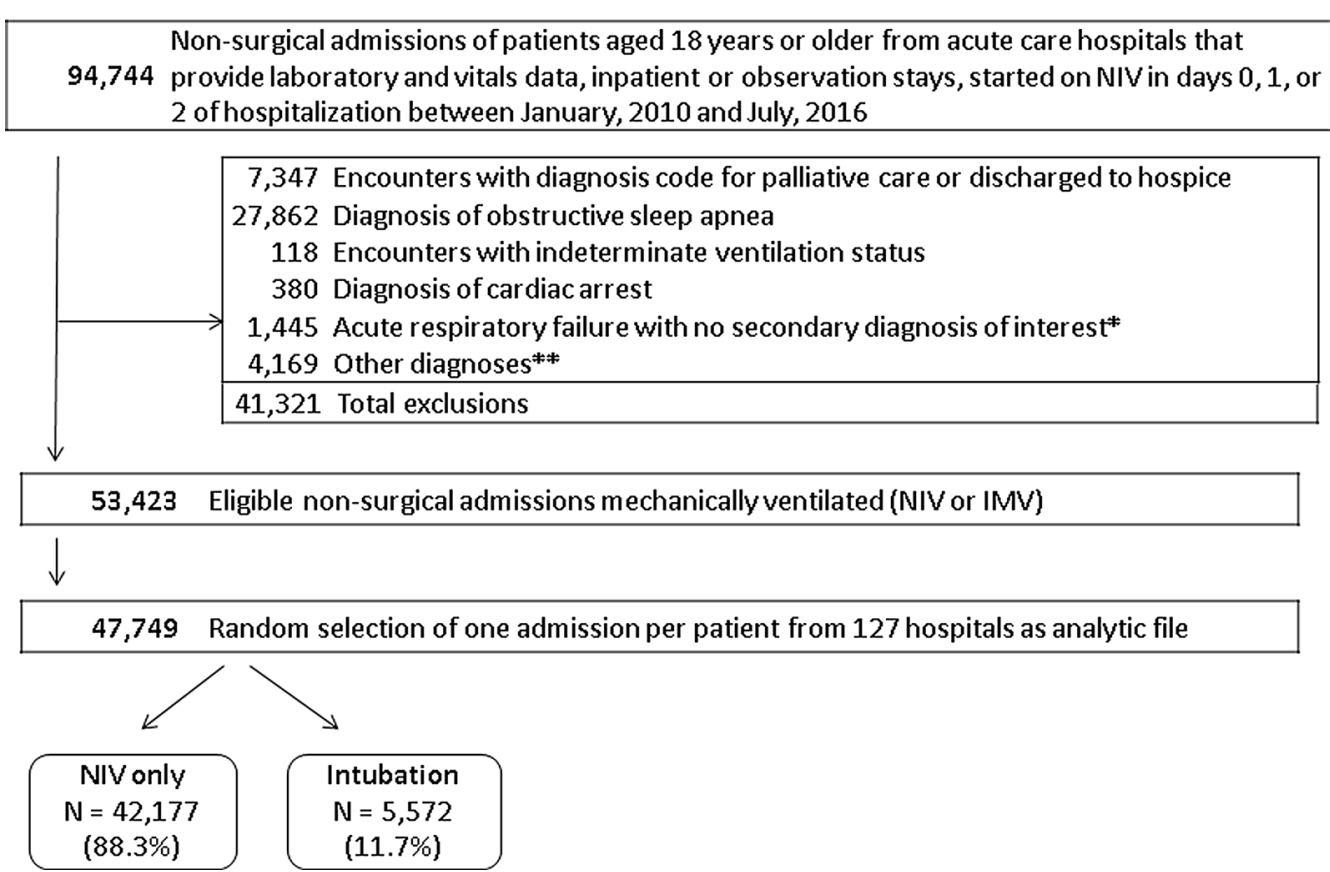

Fig. 1 Patient selection flow chart

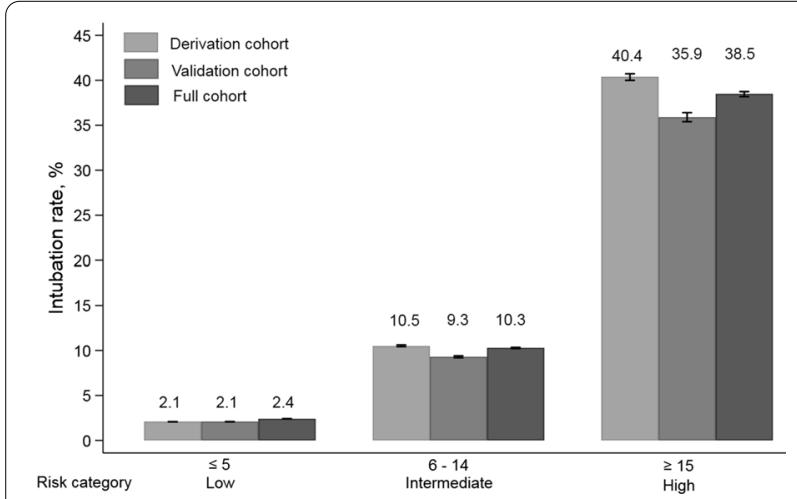

Fig. 2 Risk score categories and associated probability of intubation

and hypo-ventilated due to their primary diagnosis and consequently became hypoxic or hypercarbic, triggering the use of NIV. While it is true that these are not standard indications for NIV, our data reflect routine care in a large unselected population.

Organ failure was a strong predictor for intubation or NIV failure and patients with two or more organ failures were five times more likely to experience failure than those without organ failure. Although there is strong evidence that organ failure is an important risk factor for intubation or NIV failure, in this real-world cohort $35 \%$ of patients treated with NIV and $62 \%$ of those who failed
NIV had at least one organ failure. This scoring system could help providers to be more vigilant when choosing to deliver NIV to a patient with relative contraindications for NIV.

The results of our study should be interpreted considering its limitations. First, we did not have data on clinical assessments at the 1-2 $\mathrm{h}$ time point after initiation of NIV, findings that have been shown to predict NIV success [24]. Nevertheless, our model was intended to provide prognostic information at the time of NIV initiation. Evaluating the response to the NIV is a key aspect of management. However, once the follow-up assessment is made with our risk score, one can adjust the initial prediction (aka 'prior probability') based on the new information. Second, our outcome was NIV intubation and did not take in account the competing risk of death $(8.9 \%$ of patients died without being intubated). For this reason, we have also developed a predictive score for intubation or death. Third, we relied on ICD-9CM and ICD-10CM diagnostic codes which could have resulted in misclassification. Fourth, we lacked information on advance directive status and therefore patients with a do-not-intubate status could have been retained in the cohort. Fifth although the prediction model was validated via a temporal external cohort, future validation in another cohort including additional sites is needed. Sixth, we did not have information about the use of high flow nasal oxygen in this population. Finally, this model does not apply to 
surgical patients or those with OSA who were excluded from the cohort.

\section{Conclusions}

Clinical variables at the time of admission can be used to accurately predict the risk of intubation and of intubation or death, in a broad sample of hospitalized patients using readily available clinical data. The prognostic score may provide quantitative guidance for decision-making about patients with acute respiratory failure who may require conventional mechanical ventilation. Although multiple risk scores for intubation or NIV failure exist few are utilized in routine care. Our score which is applicable to any adult patient for whom a provider is considering NIV could be built in a web-based calculator for easy use at the point-of-care.

\section{Supplementary Information}

The online version contains supplementary material available at https://doi. org/10.1186/s12890-021-01421-w.

Additional file 1: Figure E1: Observed vs. Predicted intubation in derivation and validation cohorts. Figure E2: Example of total score and risk of intubation for patients satisfying certain conditions from the model. Table E1: Characteristics of patients with and without intubation. ${ }^{\S}$ Conditions identified as organ failure include: cardiovascular failure/shock, renal failure, neurological failure, hematological failure, hepatic failure, acidosis *measured on same day as NIV initiation (days 0 or 1 or 2). TKruskal-Wallis test. \#Chi-square test. ^Missing values among patients: 9081 (19\%) for BMl; 929 (1.9\%) for respiratory rate; 2551 (5.3\%) for systolic blood pressure. These were grouped as separate categories and included in all analyses. Table E2: Characteristics of patients in derivation and validation cohorts for intubation outcome. ${ }^{\S}$ Conditions identified as organ failure include: cardiovascular failure/shock, renal failure, neurological failure, hematological failure, hepatic failure, acidosis. *measured on same day as NIV initiation (days 0 or 1 or 2). †Kruskal-Wallis test. \#Chi-square test. $\wedge$ Missing values among patients: 9081 (19\%) for BMl; 929 (1.9\%) for respiratory rate; 2551 (5.3\%) for systolic blood pressure. These were grouped as separate categories and included in all analyses.

\section{Acknowledgements}

Not applicable.

\section{Authors' contributions}

MSS, AP, PSP and PKL developed the protocol. AP and PSP did the main analyses and prepared figures and tables. MSS wrote the main manuscript. All authors reviewed and interpreted the results and reviewed the manuscript. All authors read and approved the final manuscript.

\section{Funding}

Dr. Stefan was supported by grant K01HL114631 from the National Heart Lung and Blood Institute. Dr Lindenauer was supported by grant K24HL132008 from the National Heart Lung and Blood Institute. The funder had no role in data collection, management, analysis; study design, conduct, or interpretation of study findings; or the preparation, review, or approval of the manuscript submitted for publication.

\section{Availability of data and materials}

The dataset are not publicly available due to the data agreement with Cerner/ HealthFacts Company not to share the data of the hospitals contributing to the dataset. The source of data is Cerner HealthFacts https://sc-ctsi.org/resou rces/cerner-health-facts.
Ethics approval and consent to participate

This was a retrospective study using de-identified data, without any patient personal information. The Baystate Institutional Review Board waived the informed consent and approved the study.

\section{Competing interests}

Authors report no conflicts of interest or financial activities relevant to this work.

\section{Author details}

${ }^{1}$ Institute for Healthcare Delivery and Population Science, University of Massachusetts Medical School - Baystate, Springfield, MA, USA. ${ }^{2}$ Department of Medicine, University of Massachusetts Medical School - Baystate, Springfield, MA, USA. ${ }^{3}$ School of Public Health and Health Sciences, University of Massachusetts, Amherst, MA, USA. ${ }^{4}$ Division of Pulmonary and Critical Care, Department of Medicine, University of Massachusetts Medical School Baystate, Springfield, MA, USA. ${ }^{5}$ Division of Pulmonary and Critical Care, Tufts University School of Medicine, Boston, MA, USA. ${ }^{6}$ Division of Veterans Affairs, Department of Anesthesiology, Duke University Medical Center, Durham, NC, USA. ${ }^{7}$ Department of Quantitative Health Sciences, University of Massachusetts Medical School, Worcester, MA, USA.

Received: 28 October 2020 Accepted: 28 December 2020

Published online: 05 February 2021

\section{References}

1. Brochard L, Mancebo J, Wysocki M, et al. Noninvasive ventilation for acute exacerbations of chronic obstructive pulmonary disease. N Engl J Med. 1995;333(13):817-22. https://doi.org/10.1056/NEJM199509283331301.

2. Girou E, Schortgen F, Delclaux C, et al. Association of noninvasive ventilation with nosocomial infections and survival in critically ill patients. JAMA 2000;284(18):2361-7.

3. Nourdine K, Combes P, Carton MJ, Beuret P, Cannamela A, Ducreux JC Does noninvasive ventilation reduce the ICU nosocomial infection risk? A prospective clinical survey. Intensive Care Med. 1999;25(6):567-73.

4. Rochwerg B, Brochard L, Elliott MW, et al. Official ERS/ATS clinical practice guidelines: noninvasive ventilation for acute respiratory failure. Eur Respir J. 2017. https://doi.org/10.1183/13993003.02426-2016.

5. Conti G, Antonelli M, Navalesi P, et al. Noninvasive vs. conventional mechanical ventilation in patients with chronic obstructive pulmonary disease after failure of medical treatment in the ward: a randomized trial. Intensive Care Med. 2002;28(12):1701-7. https://doi.org/10.1007/s0013 4-002-1478-0.

6. Peter JV, Moran JL, Phillips-Hughes J, Graham P, Bersten AD. Effect of noninvasive positive pressure ventilation (NIPPV) on mortality in patients with acute cardiogenic pulmonary oedema: a meta-analysis. Lancet. 2006;367(9517):1155-63. https://doi.org/10.1016/S0140-6736(06)68506 $-1$.

7. Gray A, Goodacre S, Newby DE, et al. Noninvasive ventilation in acute cardiogenic pulmonary edema. N Engl J Med. 2008;359(2):142-51. https ://doi.org/10.1056/NEJMoa0707992.

8. Keenan SP, SinuffT, Cook DJ, Hill NS. Does noninvasive positive pressure ventilation improve outcome in acute hypoxemic respiratory failure? A systematic review. Crit Care Med. 2004;32(12):2516-23.

9. Stefan MS, Priya A, Pekow PS, et al. The comparative effectiveness of noninvasive and invasive ventilation in patients with pneumonia. J Crit Care. 2018;43:190-6. https://doi.org/10.1016/j.jcrc.2017.05.023.

10. Confalonieri M, Potena A, Carbone G, Porta RD, Tolley EA, Umberto MG. Acute respiratory failure in patients with severe community-acquired pneumonia. A prospective randomized evaluation of noninvasive ventilation. Am J Respir Crit Care Med. 1999;160(5 Pt 1):1585-91.

11. Chandra D, Stamm JA, Taylor B, et al. Outcomes of noninvasive ventilation for acute exacerbations of chronic obstructive pulmonary disease in the United States, 1998-2008. Am J Respir Crit Care Med. 2011;185(2):152-9. https://doi.org/10.1164/rccm.201106-1094OC.

12. Lindenauer PK, Stefan MS, Shieh MS, Pekow PS, Rothberg MB, Hill NS. Hospital patterns of mechanical ventilation for patients with exacerbations of COPD. Ann Am Thorac Soc. 2015;12(3):402-9. https://doi. org/10.1513/AnnalsATS.201407-2930C. 
13. Stefan MS, Nathanson BH, Priya A, et al. Hospitals' patterns of use of noninvasive ventilation in patients with asthma exacerbation. Chest. 2016;149(3):729-36. https://doi.org/10.1016/j.chest.2015.12.013.

14. Ozsancak Ugurlu A, Sidhom SS, Khodabandeh A, et al. Use and outcomes of noninvasive positive pressure ventilation in acute care hospitals in Massachusetts. Chest. 2014;145(5):964-71. https://doi.org/10.1378/chest .13-1707.

15. Antonelli M, Conti G, Moro ML, et al. Predictors of failure of noninvasive positive pressure ventilation in patients with acute hypoxemic respiratory failure: a multi-center study. Intensive Care Med. 2001;27(11):1718-28. https://doi.org/10.1007/s00134-001-1114-4.

16. Stefan MS, Nathanson BH, Lagu T, et al. Outcomes of noninvasive and invasive ventilation in patients hospitalized with asthma exacerbation Ann Am Thorac Soc. 2016. https://doi.org/10.1513/AnnalsATS.20151 0-7010C.

17. Demoule A, Girou E, Richard JC, Taille S, Brochard L. Benefits and risks of success or failure of noninvasive ventilation. Intensive Care Med. 2006;32(11):1756-65. https://doi.org/10.1007/s00134-006-0324-1.

18. Davidson AC. British thoracic society guideline group for the ventilatory management of acute hypercapnic respiratory failure in adults. Managing acute hypercapnic respiratory failure in adults: where do we need to get to? Thorax. 2016;71(4):297-8. https://doi.org/10.1136/thoraxjnl-2016208281.

19. Davies M, Allen M, Bentley A, et al. British thoracic society quality standards for acute noninvasive ventilation in adults. BMJ Open Respir Res. 2018;5(1):e000283. https://doi.org/10.1136/bmjresp-2018-000283.

20. Hedsund C, Ankjærgaard KL, Rasmussen DB, et al. NIV for acute respiratory failure in COPD: high in-hospital mortality is determined by patient selection. Eur Clin Respir J. 2019;6(1):1571332. https://doi. org/10.1080/20018525.2019.1571332.

21. Adda M, Coquet I, Darmon M, Thiery G, Schlemmer B, Azoulay E. Predictors of noninvasive ventilation failure in patients with hematologic malignancy and acute respiratory failure. Crit Care Med. 2008;36(10):2766-72. https://doi.org/10.1097/CCM.0b013e31818699f6.

22. Confalonieri M, Garuti G, Cattaruzza MS, et al. A chart of failure risk for noninvasive ventilation in patients with COPD exacerbation. Eur Respir J. 2005;25(2):348-55. https://doi.org/10.1183/09031936.05.00085304.

23. Ucgun I, Metintas $M$, Moral H, Alatas F, Yildirim H, Erginel S. Predictors of hospital outcome and intubation in COPD patients admitted to the respiratory ICU for acute hypercapnic respiratory failure. Respir Med. 2006;100(1):66-74. https://doi.org/10.1016/j.rmed.2005.04.005.

24. Duan J, Han X, Bai L, Zhou L, Huang S. Assessment of heart rate, acidosis, consciousness, oxygenation, and respiratory rate to predict noninvasive ventilation failure in hypoxemic patients. Intensive Care Med. 2017;43(2):192-9. https://doi.org/10.1007/s00134-016-4601-3.

25. Stefan MS, Nathanson BH, Higgins T, Steingrub JS, Lagu T, P.K. L. validity of noninvasive and invasive ventilation billing and procedure codes in patients with acute respiratory failure; 2014.

26. Dombrovskiy VY, Martin AA, Sunderram J, Paz HL. Rapid increase in hospitalization and mortality rates for severe sepsis in the United States: a trend analysis from 1993 to 2003. Crit Care Med. 2007;35(5):1244-50. https://doi.org/10.1097/01.CCM.0000261890.41311.E9.
27. Martin GS, Mannino DM, Eaton S, Moss M. The epidemiology of sepsis in the United States from 1979 through 2000. N Engl J Med. 2003;348(16):1546-54. https://doi.org/10.1056/NEJMoa022139.

28. Escobar GJ, Gardner MN, Greene JD, Draper D, Kipnis P. Risk-adjusting hospital mortality using a comprehensive electronic record in an integrated health care delivery system. Med Care. 2013;51(5):446-53. https:// doi.org/10.1097/MLR.0b013e3182881c8e.

29. Escobar GJ, Greene JD, Gardner MN, Marelich GP, Quick B, Kipnis P. Intrahospital transfers to a higher level of care: contribution to total hospital and intensive care unit (ICU) mortality and length of stay (LOS). J Hosp Med. 2011;6(2):74-80. https://doi.org/10.1002/jhm.817.

30. Austin PC. Using the standardized difference to compare the prevalence of a binary variable between two groups in observational research. Commun Stat Simul Comput. 2009;38(6):1228-34. https://doi. org/10.1080/03610910902859574.

31. Steyerberg EW. Clinical prediction models: a practical approach to development, validation, and updating. Berlin: Springer; 2008.

32. Hanley JA, McNeil BJ. The meaning and use of the area under a receiver operating characteristic (ROC) curve. Radiology. 1982;143(1):29-36. https ://doi.org/10.1148/radiology.143.1.7063747.

33. Tibshirani R. Regression shrinkage and selection via the LASSO. J R Stat Soc Ser B (Methodol). 1996;58(1):267-88.

34. Kohavi R. A study of cross-validation and bootstrap for accuracy estimation and model selection. In: IJCAI'95: proceedings of the 14th international joint conference on Artificial intelligence, vol. 2. p. 7.

35. lasonos A, et al. How to build and interpret a nomogram for cancer prognosis._PubMed_NCBI. http://www.ncbi.n/m.nih.gov/pubme $\mathrm{d} /$ ?term $=$ Jasonos $+\mathrm{A} \% 2 \mathrm{C}+$ Schrag $+\mathrm{D} \% 3 \mathrm{~B}+\mathrm{JClin}+$ Oncol +2008 . Accessed 2 July 2019

36. Parker K, Perikala V, Aminazad A, et al. Models of care for noninvasive ventilation in the acute COPD comparison of three tertiary hospitals (ACT3) study. Respirology. 2018;23(5):492-7. https://doi.org/10.1111/resp.13228.

37. Myers LC, Faridi MK, Currier P, Camargo CA. ICU utilization for patients with acute exacerbation of chronic obstructive pulmonary disease receiving noninvasive ventilation. Crit Care Med. 2019;47(5):677-84. https://doi. org/10.1097/CCM.0000000000003660.

38. Fiorino S, Bacchi-Reggiani L, Detotto E, et al. Efficacy of noninvasive mechanical ventilation in the general ward in patients with chronic obstructive pulmonary disease admitted for hypercapnic acute respiratory failure and $\mathrm{pH}<$ 7.35: a feasibility pilot study. Intern Med J. 2015;45(5):527-37. https://doi.org/10.1111/imj.12726.

39. Yalcinsoy M, Salturk C, Oztas S, et al. Can patients with moderate to severe acute respiratory failure from COPD be treated safely with noninvasive mechanical ventilation on the ward? Int J Chron Obstruct Pulmon Dis. 2016;11:1151-60. https://doi.org/10.2147/COPD.S104801.

\section{Publisher's Note}

Springer Nature remains neutral with regard to jurisdictional claims in published maps and institutional affiliations.

\footnotetext{
Ready to submit your research? Choose BMC and benefit from:

- fast, convenient online submission

- thorough peer review by experienced researchers in your field

- rapid publication on acceptance

- support for research data, including large and complex data types

- gold Open Access which fosters wider collaboration and increased citations

- maximum visibility for your research: over 100M website views per year
}

At $\mathrm{BMC}$, research is always in progress.

Learn more biomedcentral.com/submissions 